\title{
Juventude, violência e lazer: Quais são as publicações no Portal CAPES - Brasil?
}

\author{
Youth, violence and leisure: What has been published at CAPES data base Brazil? \\ Juventud, violencia y ocio: ¿Cuáles son las publicaciones en el Portal CAPES Brasil?
}

Recebido: 21/06/2021 | Revisado: 29/06/2021 | Aceito: 06/07/2021 | Publicado: 16/07/2021

\author{
Adriana Goncalves Queiroz \\ ORCID: https://orcid.org/0000-0002-0634-9022 \\ Universidade Federal de Pernambuco, Brasil \\ E-mail: adrianaqueiroz.to@gmail.com \\ Sheylazarth Presciliana Ribeiro \\ ORCID: https://orcid.org/0000-0003-4768-9135 \\ Universidade Estadual de Minas Gerais, Brasil \\ E-mail: sheylazarth.ribeiro@uemg.br \\ Gildo Garcia da Rocha Júnior \\ ORCID: https://orcid.org/0000-0002-9946-0490 \\ Secretaria de Estado de Educação de Minas Gerais, Brasil \\ E-mail: gildo.junior @educacao.mg.gov.br. \\ Ana Cláudia Porfirio Couto \\ ORCID: https://orcid.org/0000-0003-3457-0987 \\ Universidade Federal de Minas Gerais, Brasil \\ E-mail: acpcouto@gmail.com
}

\begin{abstract}
Resumo
Em uma análise dos temas lazer, juventude e violência, o Grupo de Estudos em Sociologia e Pedagogia em Esporte e Lazer, da Universidade Federal de Minas Gerais, investigou, usando ferramentas de buscas avançadas, no Portal da Coordenação de Aperfeiçoamento de Pessoal de Nível Superior (CAPES), as publicações entre 2014-2019, as quais articulam esses constructos. Objetivou se apresentar evidências atualizadas sobre o tema e busca auxiliar na reflexão de ações contextualizadas que incluam o lazer para o público jovem. Foram encontrados 11 artigos quando a busca era por binômios, dos quais 7 referentes a lazer e juventude e 4 referentes a lazer e violência. Os pesquisadores concluem que os artigos encontrados no referido portal - 58 do conceito lazer, 4 do binômio lazer e violência e 7 que apresentavam os descritores juventude, violência e exemplos de vivências de lazer - estão concentrados em pesquisadores da sociologia, psicologia, estudos culturais e em pouca expressão nos estudos do lazer. Observa-se pouca contribuição dos pesquisadores do campo do lazer que abordam a articulação de juventude e violência. Contudo, todos os artigos de alguma forma citaram os três temas, ressaltando a importância do desenvolvimento de estudos densos sobre o assunto, que ganha grande relevância no mundo contemporâneo.
\end{abstract}

Palavras-chave: Lazer e educação; Juventude; Violência juvenil; Lazer e violência; Juventude e violência.

\begin{abstract}
In an analysis of the themes leisure, youth and violence, the Study Group on Sociology and Pedagogy in Sport and Leisure at the Federal University of Minas Gerais investigated, using advanced search tools, on the Coordenação de Aperfeiçoamento de Pessoal de Nível Superior (CAPES) Database, the publications, from 2014 to 2019, that articulate these constructs. The objective was to present updated evidence about the theme and bring contextualized actions and reflections that include leisure of a young public. 11 articles were found when the search was for binomials. Being found 7 referring to leisure and youth and 4 - leisure and violence. GESPEL researchers conclude that the articles found - 58 of which were leisure, 4 were leisure and violence and 7 had the descriptors youth, violence, and examples of leisure experiences - are concentrated in researchers from sociology, psychology, cultural studies and little expression in leisure studies, which shows little contribution from researchers in the field of leisure who approach the articulation with youth and violence. However, all articles cited the three themes in some way, emphasizing the importance of developing dense studies on the subject, which is of great relevance in the contemporary world.
\end{abstract}

Keywords: Leisure and education; Youth; Youth violence; Leisure and violence; Youth and violence.

\section{Resumen}

En un análisis de los temas de ocio, juventud y violencia, el Grupo de Estudio sobre Sociología y Pedagogía en el Deporte y el Ocio, de la Universidad Federal de Minas Gerais [UFMG], investigó, utilizando herramientas de búsqueda avanzada, 
en el Portal de la Coordenação de Aperfeiçoamento de Pessoal de Nível Superior (CAPES), las publicaciones, de los últimos cinco años, que articulan esas construcciones. El objetivo fue presentar evidencia actualizada sobre el tema y buscar ayudar a reflexionar sobre acciones contextualizadas que incluyen el ocio para los jóvenes. Se encontraron 11 artículos cuando la búsqueda era por binomios, siendo que 7 de los binomios violencia y juventud, 4 referentes a ocio y violencia. Los investigadores concluyen que los artículos encontrados en el referido portal - 58 del concepto de ocio, 4 del binomio ocio y violencia y 7 que tienen los descriptores juventud, violencia y ejemplos de experiencias de ocio - se concentran en investigadores de sociología, psicología, estudios culturales y poca expresión en el estudio del ocio, lo que muestra poca contribución de los investigadores en el campo del ocio que abordan la articulación con la juventud y la violencia. Sin embargo, todos los artículos citaron los tres temas de alguna manera, enfatizando la importancia de desarrollar estudios densos sobre el tema, lo cual es de gran relevancia en el mundo contemporáneo.

Palabras clave: Ocio y educación; Juventud; Violencia juvenil; Ocio y violencia; Juventud y violencia.

\section{Introdução}

O constructo lazer tem sido analisado por diversas perspectivas ao longo dos anos, sendo abordado desde um viés histórico (Jacob, 2014; Azevedo, Hutz, Nunes, \& Pires, 2014), até estudos filosóficos, os quais refletem sobre o lazer e a fenomenologia (Menin, 2018). Além desses, há aqueles que apresentam reflexões no tempo/espaço no lazer (Miranda, 2016) e os que refletem sobre a sociedade, articulando os fenômenos à obra de Marx e Engels (Mendonça, 2014).

Pesquisas no campo da gestão também têm encontrado seu lugar nos estudos do lazer. Desde a dinâmica de setores em cidades pequenas (Fonseca \& Oliveira, 2014) aos megaeventos (Couto, Ribeiro, Scopel, Fróis, \& Lemos, 2015), perpassando, inclusive, pela relação lazer e turismo (Marques \& Silva, 2017; Cabral, Dias, Santiago, \& Gomes, 2015; Melo \& Dias, 2014).

A mídia também tem sido incluída em pesquisas sobre o lazer, principalmente ao se considerar o papel de sua influência na sociedade (Castro \& Silva, 2018; Labegalline, Rodrigues, Almeida, Bueno, Baldissera, \& Nogueira, 2016; Cavicholli \& Almeida, 2014). Outro nicho importante tem sido a formação profissional no lazer, desde os cursos técnicos (Isayama \& Santos, 2014) e de graduação (Cruz A. \& Cruz S., 2016) à relação dessa formação com as políticas públicas (Isayama \& Ungheri, 2017).

Para além das políticas públicas (Schwartz \& Tavares, 2014) e dimensões sociais (Marcelinno \& Puke, 2014; Elizalde \& Gomes, 2014; Costa \& Sampaio, 2015), a relação com o estado, com o trabalho (Almeida, Neri, \& Wiggers, 2014; Pereira, 2015; Barros, 2016), com o esporte (Ramos \& Isayama (2009) e com a intersetorialidade (Carvalho \& Warschauer, 2015), o lazer também tem sido estudado com foco no público a quem ele se destina ou que o vivencia. Desde usuários em hemodiálise (Fritsch, Dudel Mayer, Ubessi, Kirchne, Barbosa, \& Fernande Stumm, 2015) e idosos (Miranda \& Rezende, 2015; Araújo \& Rocha, 2016; Pegorari, Santos \& Tavares, 2015; Carneiro, Martinelli, \& Rueda, 2014) a atletas (Doll \& Oliveira, 2017) e a relação entre praticantes de lazer e a comunidade em seu entorno (Boclin, Faerstein, \& Leon, 2014).

O Grupo de Estudos em Sociologia e Pedagogia do Lazer [GESPEL] da Universidade Federal de Minas Gerais [UFMG] tem desenvolvido pesquisas que estudam a relação do lazer com diferentes públicos e contextos (Amorim, Campos, Couto, \& Lemos, 2019; Rocha et al., 2018; Queiroz, 2015). Uma das relações que tem interessado os pesquisadores do GESPEL nos últimos anos tangencia o lazer e a juventude.

Nas produções do grupo, a juventude tem sido entendida como diversa e plural, com modos de vida distintos e diferentes formas de ocupar espaços e territórios (Rocha, 2019). Trabalhos como Rocha (2019), Pachêco (2019), Silva, da Silva e Couto (2019) e Rezende (2019) mostram como as juventudes nos lazeres são marcadas por questões de raça, gênero, etnia, religião, lugares que habitam etc., sendo que um elemento que tem presença constante nos estudos entre lazer e juventude é a violência, presente de forma circundante, de cenário ou transversal. 
Diante do avanço do crescente número de pesquisas no campo do lazer e de sua variedade, o grupo, portanto, se questionou: o que os pesquisadores têm publicado sobre o entrelaçamento dos temas juventude, lazer e violência? Somado a isso, uma vez que muitas pesquisas brasileiras utilizam o Portal da Coordenação de Aperfeiçoamento de Pessoal de Nível Superior [CAPES] como ponto de partida ou de complementaridade de seus estudos, o que tem sido publicado sobre esse entrelaçamento, no maior fomentador de divulgação da pesquisa brasileira: o Portal CAPES?

Ao se lançar na busca de respostas a essas perguntas, por meio de revisão narrativa, o GESPEL objetiva apresentar evidências atualizadas sobre o tema e busca auxiliar na reflexão de ações contextualizadas que incluam o lazer para o público jovem.

\subsection{O Portal CAPES}

No sistema educacional de nível superior brasileiro, o Portal CAPES é constantemente difundido como fonte de evidência e pesquisa. É gratuito, pode ser acessado de casa e serve como base para muitos estudantes de graduação e/ou pós-graduação e pesquisadores, noviços ou experientes. O Portal CAPES (2019) se apresenta como "um Portal de Periódicos, da Coordenação de Aperfeiçoamento de Pessoal de Nível Superior (CAPES), uma biblioteca virtual que reúne e disponibiliza a instituições de ensino e pesquisa no Brasil o melhor da produção científica internacional”.

\section{Metodologia}

Este artigo apresenta uma pesquisa qualitativa cuja interpretação dos autores é importante, os dados são apresentados de forma descritiva e a análise dos dados segue um processo indutivo (Pereira, 2018). Foi realizada uma revisão narrativa no Portal CAPES, o qual apresenta um setor de buscas dividido por "assunto", "periódicos", "livros" e "base". A revisão narrativa é uma revisão mais abrangente, com possibilidade e de temática abrangente e que não exige protocolo rígido como a revisão sistemática. Na revisão narrativa a seleção de artigos serve a pergunta do autor, sendo passível de influência subjetiva do autor. (Cordeiro, Oliveira, Renteria, Guimaraes, 2007).

A busca para este texto se limitou a periódicos revisados por pares, publicados nos últimos cinco anos (2014-2019). Como direcionamento, fez-se a busca avançada pelo termo lazer e depois a seleção dos artigos pela leitura e resumo, os quais deveriam apresentar o entrelaçamento dos temas: lazer, juventude e violência.

Pesquisas também foram realizadas sob as sombrinhas conceituais juventude e violência. No entanto, não foram encontrados artigos que se remetessem aos termos dessa revisão narrativa no título ou no resumo, como explícito no critério de inclusão. Partiu-se, então, para buscas pelos binômios lazer e violência como também lazer e juventude. A análise dos artigos encontrados foi feita a partir de triangulação dos dados advindos das buscas citadas.

\section{Resultados}

Foram encontrados 58 artigos dentro da sombrinha conceitual lazer. Após leitura dos títulos e resumos, chegou-se à conclusão de que eles não satisfazem à pergunta deste artigo. Não foram encontrados artigos que entrelaçam os temas dentro das outras sombrinhas conceituais: juventude e violência.

Em busca pelo binômio lazer e violência, foram encontrados 4 artigos. Porém, no binômio lazer e juventude, foram encontrados 7 artigos que apresentavam os descritores juventude, violência e exemplos de vivências de lazer (por exemplo: dança, 
música e esporte). Essa nova configuração, ainda que saísse do escopo proposto, serviu à função de subsidiar reflexões dos autores neste artigo, entrelaçando os temas.

\subsection{Lazer e juventude no Portal CAPES}

A concomitante busca pelos termos lazer e juventude no Portal CAPES teve como resultado os trabalhos de Almeida e Siebra (2015); Pinto e Silva (2016); Pines e Uvinha (2015); Franca, Gonçalves e Rechia (2016); Moraes (2017); Nasser, Branco, Lara, Del Vechio, Winer, Mesquita, Souza, Silva e Jansen (2016), e Keitel, Kleba e Sebenello (2016).

Almeida et. al (2015) realizaram uma pesquisa na cidade de Barcelona buscando compreender como os frequentadores se relacionam com os espaços com potencial lúdico. Para os autores "as transformações das urbes ocorreram em consequência do desenvolvimento industrial, da urbanização e dos meios de comunicação, sendo responsáveis pela diminuição da transmissão da cultura lúdica entre crianças, adolescentes e adultos” (p. 173). Nas praças estudadas, a população infanto-juvenil valoriza equipamentos amplos e locais com grupos de pessoas para brincar; equipamentos para desenvolvimento das competências motrizes; a duração do ato lúdico; segurança; convivência com adultos; autonomia e espontaneidade com as brincadeiras; diversidade dos jogos e brincadeiras.

Pinto e Silva (2016) tiveram o objetivo de "identificar as representações de lazer na população jovem da cidade de Santa Cruz do Capibaribe-PE”. Executaram um trabalho de questionários semiestruturados com 40 jovens (estudantes e não estudantes de 12 a 19 anos, de ambos os sexos). Os resultados apontam que os jovens têm pensam o lazer confundindo com "tempo livre" e "necessidades fisiológicas" (como descansar). As atividades que os autores definem como lazer são restritas e eles ainda indicam a importância "da criação de um plano diretor na cidade que contemple áreas de lazer voltadas à prática dos esportes, recreação e lazer da população" (p.1).

Pines e Uvinha (2015) estudaram os jovens, a atividade física como opção de lazer em um equipamento de lazer de São Paulo. Os autores adotaram uma pesquisa qualitativa, com a aplicação de entrevistas semiestruturadas com 15 jovens que participam das ações do Serviço Social de Comércio [SESC] Consolação, bem como um administrador da área de atividade física. Como conclusão as entrevistas mostram a forte relação dos jovens com as atividades físicas e a influência da mídia nessas práticas. "Os jovens preferem praticar as atividades físicas na unidade, contudo, o administrador da unidade pesquisada no SESC expressou a necessidade de desenvolver mais projetos para atender esse público" (p. 361).

Franca et al. (2016), a partir da questão "Educação Física Escolar pode contribuir para o fortalecimento da identidade local, sem deixar de lado sua especificidade?” (p. 69), criaram um roteiro de observação e abordagem aos estudantes em uma semana festiva de uma escola de Curitiba/PR. Os autores concluíram que o evento se concretizou como uma das possibilidades de educar alunos e alunas para o lazer (p. 69).

Moraes (2017), usou questionários para investigar a existência de diferenças lazer de estudantes que moravam próximos diferentes estruturas esportivas. Ele realizou um amplo trabalho, "estudo transversal, com 389 crianças e adolescentes, de ambos os sexos, com idades entre sete e 17 anos, estudantes da rede pública da zona urbana do município de Santa Cruz do Sul-RS" (Moraes, 2017, p. 302). Como resultado, o autor apresenta que as estruturas esportivas no entorno da escola dos estudantes são homogêneas. Existe prevalência de estudantes que "nunca/às vezes realizam ao menos 30 minutos de atividades físicas moderadas/intensas. Essa proporção alcançou 69,2\% das meninas e 37,6\% dos meninos, em escolas com alta presença de estrutura em seu entorno, e 70,6\% das meninas e 47,4\% dos meninos, em escolas com baixa estrutura em seu entorno" (Moraes, 2017, p. 
302). A conclusão é de que em escolas com alta presença de estruturas de atividades físicas em seu entorno possibilitam maior frequência de atividade física entre estudantes.

Nasser et al. (2016) associou a prática de atividade física de lazer e o uso de substâncias lícitas (tabaco) entre 1953 adultos jovens (de 18 a 35 anos de idade) de Pelotas-RS (Brasil). Como resultado, identificou-se que jovens ativos em atividade física de lazer foi de $25,3 \%$ e esteve associada a ser do sexo masculino e não fazer uso diário de tabaco. Foi identificado, ainda que "as mulheres de maior idade e de estratos econômicos inferiores são as que fazem mais uso de tabaco entre os sujeitos estudados" (p. $63)$.

Keitel et al. (2016) debatem as relações entre juventude, lazer e risco (segurança), do ponto de vista dos profissionais da Rede de Atendimento à Infância e Adolescência [RAIA] de Chapecó. O objetivo dos autores foi entender o que jovens e seus pais, vinculados ao Serviço de Convivência de Fortalecimento de Vínculo da Secretaria reconhecem como práticas locais de lazer e riscos associados.

O método do trabalho foram grupos focais e a analise a partir da identificação de temáticas centrais pautadas em teorias. Nessa pesquisa, "uma das perguntas essenciais que marcou o diálogo com as falas dos participantes foi a seguinte questão: qual é o lugar que os jovens têm para se encontrar e para crescerem juntos na comunidade?” (Keitel et al. 2016, p. 53). Os autores identificaram que existem discursos patologizantes das práticas dos jovens quanto ao lazer, relacionando-as aos riscos de sua segurança física e mental.

Ainda segundo de Keitel et al. (2016) são necessários espaços públicos e nas famílias que ajudem os jovens a reconhecerem as mudanças de interesses no processo de crescimento, bem como criar estratégias de construção de autonomia com monitoramento gradual dos jovens, para que possam refletir sobre suas escolhas, principalmente diante de riscos, como o uso de álcool e outras substâncias. Quanto ao contato dos jovens com o álcool, um dos espaços apontados para esse contato são nas próprias famílias. As falas dos grupos revelam que eles buscam outros espaços e espaços escondidos como exercício de autonomia (que indica as estratégias repressoras e de negação pouco têm funcionado como estratégias protetivas). Desse modo, os autores recomendam a necessidade de transcender acepções de controle de risco e investir em espaços de integração social entre jovens, dos jovens com suas famílias e com a comunidade.

Ressalta-se que, apesar de não terem sido encontrados artigos que articulassem lazer, juventude e violência, o trabalho de Keitel et al. (2016) aproxima das temáticas dessa pesquisa quando aborda o entendimento dos jovens e de seus pais sobre as práticas de lazer e seus riscos. E, nas demais pesquisas, a temática da violência aparece algumas vezes dissolvida no texto, sem um tratamento principal.

\subsection{Lazer e Violência no Portal CAPES}

A busca pelos termos violência e lazer no Portal CAPES teve como resultado os trabalhos Andrade, Batistella e Jimenez (2016), com a temática drogas; de Trotta (2016), que trabalha com a música funk; de Madeira e Rodrigues (2015), os quais pesquisaram o programa de segurança pública Pronasci, e Teixeira (2018), abordando as torcidas organizadas de futebol.

Andrade et al. (2016) analisaram artigos brasileiros publicados entre 2004 e 2014 com as temáticas de atos infracionais e o uso de drogas na adolescência. Concluíram que os fatores estruturais, psicossociais e individuais podem expor ou proteger o adolescente nas situações estudadas. A revisão dos autores apontou que as atividades de lazer só foram pesquisadas no que se refere ao uso de drogas e que ambos os grupos de adolescentes estudados (usuários e não usuários) elegem diferentes atividades de lazer para vivenciar. Destaca-se dentre estas a prática religiosa como um importante fator protetor. 
Trotta (2016) discutiu a experiência musical e o incômodo aos ouvintes, "irritando e intimidando aqueles que não compartilham do prazer de ouvir determinado repertório" (Trotta, 2016, p. 86). Ele aborda o caso do funk como "gênero musical brasileiro com histórica vinculação com o contexto das periferias, morros e favelas e que volta a surgir como tema privilegiado na mídia a partir de seu uso nos fenômenos dos rolezinhos, causando incômodo e rechaço" (Trotta, 2016, p. 88).

Entendendo o funk como uma cultura articulada ao lazer e à juventude, o trabalho de Trotta (2016) abordou de forma indireta a violência quando conclui que pensar sobre o incômodo do popular-funkeiro-periférico significa reprocessar ideias sobre a desigualdade social, num contexto de grandes transformações sociais, políticas e comportamentais no Brasil e no mundo.

Madeira et al. (2015) pesquisou a orientação das políticas de segurança pública focando o Programa Nacional de Segurança Pública com Cidadania [Pronasci]. Esse é foi um programa do governo federal brasileiro voltado para juventude em vulnerabilidade social. Os autores mostram as trajetórias da implementação de um novo paradigma da política pública no que tange à segurança, e toma-se como modelo o processo de descentralização, que faz dos municípios atores-chave da gestão em segurança pública, atuando em cooperação com os outros entes federativos, como estados e União.

O Pronasci como uma ação de atividades de lazer (esporte) dirigida para jovens demonstra uma ação governamental pensada para o grupo e que se apoia em um conceito interacional de segurança cidadã.

Teixeira (2018) pesquisa a criação da Associação Nacional das Torcidas Organizadas [Anatorg] em 2014 considerado pela autora um "marco na história do associativismo torcedor no Brasil" (Teixeira, 2018, p. 01). Esse marco existe em função do fato inédito de iniciativas do poder público para prevenir a violência em estádios e se preocupar com a criminalização do torcer. Como resultado, a autora encontrou resistências à coalizão nacional dentro da Anatorg, especialmente por parte de membros de torcidas organizadas envolvidos em "episódios violentos e que rejeitam a ideia de aliar-se a agrupamentos considerados inimigos" (Teixeira, 2018, p. 11). A autora mostra que

a ocorrência de confrontos violentos reafirma a visão disseminada de que agremiações são perigosas e de que devem ser banidas do futebol profissional. Contudo, os protagonistas desse movimento coletivo nacional apostam no capital simbólico acumulado ao longo do processo para se afirmarem como sujeitos de direitos e resistir às controvérsias decorrentes de suas ações e à atual crise política vivida pelo Brasil. (Teixeira, 2018, p. 11)

Os quatro artigos estudam práticas de lazer que possuem barreiras tênues entre o direito ao divertimento e situações de vulnerabilidades a crimes. A política pública Pronasci foi um programa que promovia prática de lazer para população juvenil em situação de vulnerabilidade ao crime.

O uso de drogas, geralmente, está relacionado a festas e a práticas sociais de lazer. O funk, aqui entendido em sua cultura musical, é uma manifestação cultural de um grupo social frequentemente discriminado socialmente por sua articulação à violência e ao crime. E as torcidas organizadas são atreladas a diferentes experiências sociais. Dentre estas, as brigas entre times e a depredação de patrimônio público. Essas articulações, por vezes não estudadas em profundidade, mostram, por um lado, práticas de lazer e, por outro, situações nomeadas de problemas sociais.

\section{Discussão ou Triangulação dos temas Lazer, Juventude e Violência}

As pesquisas no Portal CAPES a partir do binômio lazer e juventude nos apresentaram um grupo de sete estudos que pensam o lazer articulado à juventude. Entretanto, essas pesquisas não abordaram de forma direta, nem principal, a violência como 
fenômeno constante de práticas de lazer entre jovens ou na condição juvenil. Essa ausência ou desarticulação entre lazer e violência produz inferências para a discussão do presente artigo.

Um ponto de vista possível pressupõe que as pesquisas de lazer e violência existem partindo do campo do lazer (Bonalume, 2010. Romera, 2008). Contudo, os artigos vinculados ao Portal CAPES podem não nomear as vivências como lazer nas palavras-chaves. Somado a isso, as plataformas de descritores, como Descritores em Ciências da Saúde [DeCS], Medical Subject Headings [MeSH] e o Thesauros do Instituto Nacional de Estudos e Pesquisas Educacionais Anísio Teixeira [INEP], apresentam sinônimos restritos para a terminologia lazer.

Embora as pesquisas sobre lazer no Brasil sejam datadas do século passado, quando acessamos descritores de palavras chaves, o DeCS ${ }^{5}$ apresenta o lazer em dois termos (centros de convenções de lazer e atividades de lazer), o INEP ${ }^{6}$ apresenta quatro termos (atividades educativas não escolares, equipamentos de lazer, lazer educação e lazer educativo), os quais não estabelecem a diversidade que o lazer apresenta como campo de estudo, como descrito no dicionário crítico do lazer, por exemplo (Gomes, 2004).

Faz-se, portanto, compreensível encontrar mais artigos que apresentem vivências entendidas como lazer, por exemplo, dança, música, esporte, dentre outras, em títulos e resumos do que o constructo lazer em si. Tal declaração se tornou verdadeira quando buscas utilizando os descritores lazer e violência foram realizadas.

Nesse sentido, esta revisão identificou que, dos estudos pesquisados, 4 articulam lazer com práticas diversas, violência $\mathrm{e}$ juventude, utilizando métodos diversificados de pesquisa e elegendo como objeto orientador a prática de lazer (Andrade et al., 2016. Trotta, 2016. Madeira et al., 2015. Teixeira, 2018). Somente Keitel et. al. (2016) focou nos sujeitos adolescentes e família.

A metodologia qualitativa se fez presente como caminho para entender as relações complexas entre os temas estudados em quatro artigos. Os métodos variaram entre o uso de grupos focais, análises de documentos (revistas e jornais), análise de material etnográfico, revisão de base de periódicos, entrevistas com sujeitos da pesquisa, análise de documentação legal e observação do participante.

Considerando os resultados das pesquisas, as que abordam a prática (música funk, torcida de futebol e Pronasci) se dedicaram a construir conhecimentos sobre como essas práticas operam na sociedade e como, em alguma medida, se articulam à violência. Diferentemente, Keitel et al. (2016), ao dialogarem via grupo focal com os jovens, mostram que é necessário colocar em debate discursos sobre a relação entre jovens, lazer e risco, pois há uma acepção em culpabilizar as atitudes dos jovens.

$\mathrm{O}$ risco à segurança entendido como "vulnerabilidade do jovem diante da sua imaturidade no lazer é uma forma de reduzir as discussões, pois ignora o quanto as opções são restritas e as condutas em relação aos seus interesses são repressoras" (Keitel et al, 2016, p. 55). Isso fragiliza vivências de integração e participação social dos jovens, sem compreender o lazer como direito e sua potência na produção de experiências de desenvolvimento.

Tal afirmativa pode ser exemplificada nos artigos que focam o lazer e a juventude, uma vez que em unanimidade apontam a escassez, na comunidade, de equipamentos, locais e orientações para atividades físicas e esportivas aos jovens. Isso dificulta o reconhecimento desse do espaço, como também de sua apropriação e uso, seja para o lazer aceitável pela sociedade e que envolve atividades de força e alongamento, ou para o lazer dito nocivo, como o uso de drogas e a vivência de culturas marginalizadas.

Todos os artigos avaliados demonstram que intervenções estatais nas práticas de lazer são pilares para a consolidação de direitos sociais da juventude. Ressalta-se, no entanto, a importância da subjetividade e respeito ao lazer, em construção, e do jovem, também ainda em construção. 


\section{Considerações Finais}

A produção de artigos sobre lazer, violência e juventude no Portal da CAPES, nos últimos cinco anos, encontra-se concentrada em pesquisadores da sociologia, psicologia, estudos culturais e em pouca expressão no lazer. Esse fato mostra que objetos de pesquisas relacionados ao lazer se fortalecem pelo seu caráter interdisciplinar. Contudo, é notória a necessidade de pesquisadores do campo do lazer se empenharem nas discussões que abordem a articulação com juventude e violência.

O GESPEL, ao se aprofundar sobre a triangulação proposta (lazer, juventude e violência), observou que ainda não tem sido encontrada produção explícita sobre ela. Quando há discussão sobre um dos binômios que envolvem o lazer, haverá a presença do tema não explicitado. Sendo assim, todos os artigos de alguma forma citaram os três temas, ressaltando a importância do desenvolvimento de estudos densos sobre o assunto.

Estudos futuros que se interessem sobre as temáticas em separado juventude, lazer ou violência, devem estar cientes que estes temas não aparecem de forma segregada, pelo contrário há grande correlação entre eles, tornando estudos que se aprofundem na triangulação destes necessários e profícuos tanto para áreas da ciências humanas e sociais como para educação e saúde.

\section{Referências}

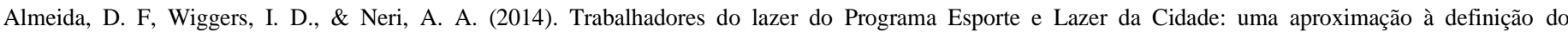
perfil. Movimento, 20 (1), 215-238. https://doi.org/10.22456/1982-8918.40525

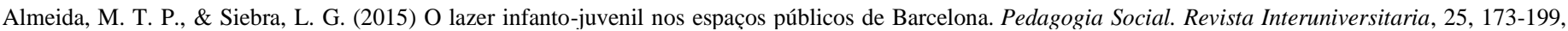
2015. https://doi.org/10.7179/PSRI_2015.25.08

Amorim, P. A. R., Campos, E. A., Couto A. C. P., \& Lemos, K. L. M. (2019). GESPEL em ação no Centro MG da Rede CEDES. Utópica Editoral.

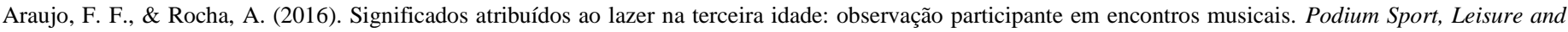
Tourism Review, 5 (2), 38-55 https://doi.org/10.5585/podium.v5i2.157

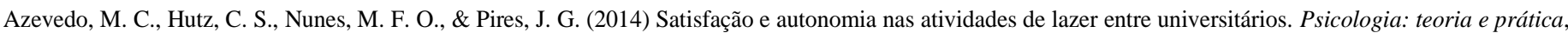
16(1), 91-103. http://pepsic.bvsalud.org/scielo.php?script=sci_abstract\&pid=S1516-36872014000100008\&lng=pt\&nrm=iso

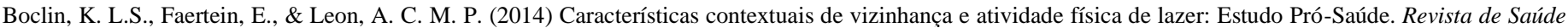
Pública, 48(2), 249-257. https://doi.org/10.1590/S0034-8910.2014048004935.

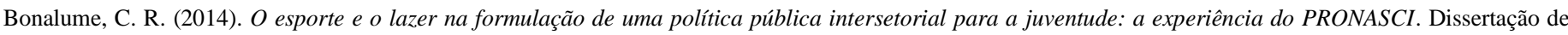
Mestrado, Programa de Pós-Graduação em Educação Física, Universidade de Brasília, Brasília, Brasil. http://repositorio.unb.br/handle/10482/6068

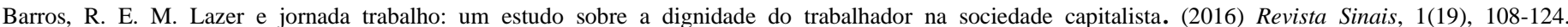
https://doi.org/10.25067/s.v1i19.12232

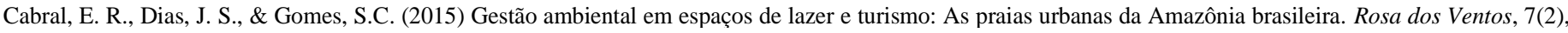
269-287. http://www.ucs.br/etc/revistas/index.php/rosadosventos/article/view/3102

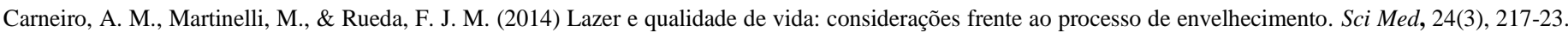
https://doi.org/10.15448/1980-6108.2014.3.16480

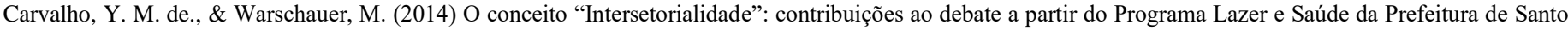
André/SP. Saúde e Sociedade, 23, 191-203. https://doi.org/10.1590/S0104-12902014000100015

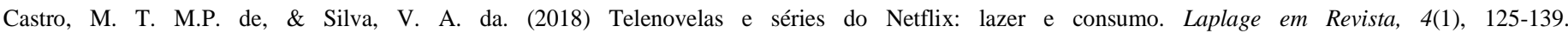
https://laplageemrevista.editorialaar.com/index.php/lpg1/article/view/355

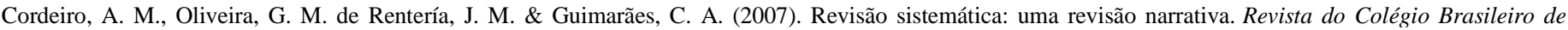
Cirurgiões, 34(6), 428-431. https://doi.org/10.1590/S0100-69912007000600012

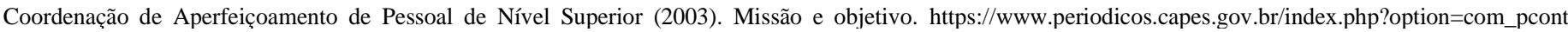
ent\&view=pcontent\&alias=missao-objetivos \&Itemid=109

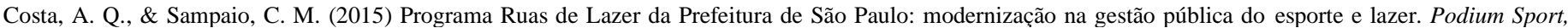
Leisure and Tourism Review, 4(2), 43-57. https://doi.org/10.5585/podium.v4i2.118 
Couto, A. C. P., Frois, R., Lemos, K. L. M., Ribeiro, S. P., \& Scopel, A. J. S. (2015) Voluntariado e megaeventos: aproximações possíveis. Revista Brasileira de Estudos do Lazer, 2(3), 123-138. https://periodicos.ufmg.br/index.php/rbel/article/view/495

Couto, A. C., Lemos, K., Rocha, P., \& Ribeiro, S. (2018) GESPEL em Ação: Grupo de Estudo em Sociologia e pedagogia do Esporte e do Lazer. Editora UFMG/ EEFFTO.

Cordeiro, A. M, Oliveira, G. M de, Renteria, J.M., \& Guimaraes, C. A. (2007) Revisão sistemática: uma revisão narrativa. Rev. Col. bras. cir. 34(6). https://doi.org/10.1590/S0100-69912007000600012

Cruz, A. C. S., \& Cruz, S. C. (2016) O conhecimento sobre o lazer no curso de Licenciatura em Educação Física da UNEB campus/DCH IV e a especificidade da Educação do Campo. Revista Brasileira de Educação do Campo, 1(2), 318-343. https://www.readcube.com/articles/10.20873\%2Fuft.2525-4863.2016v1n2p318

Doll, J., \& Oliveira, S. N. de. (2017) 'This is The End, My Beautiful Friend!' lazer sério e o fim da carreira. Educação \& realidade. 42(1), 215-236. https://doi.org/10.1590/2175-623651581

Elizalde, R., \& Gomes, C. L. (2014) Tempo livre: entendimentos enunciados por participantes de mestrados latino-americanos em lazer e recreação. Movimento, 20(2), 569-591, 2014. https://doi.org/10.22456/1982-8918.42866

Farias M., Hutz, C. S., \& Oliveira N. Análise da produção de artigos científicos sobre o lazer: Uma Revisão. Psicologia: Teoria e Pesquisa, $30(3), 2014$.

Fonseca, M. A. P., \& Oliveira E. J. (2014) Lazer e a expansão dos serviços no litoral sul potiguar. Revista de Turismo Contemporâneo, 2(1). https://periodicos.ufrn.br/turismocontemporaneo/article/view/5406

ForellL, L., \& Stigger, M. P. (2017) Trabalho voluntário em políticas públicas sociais de esporte e lazer: uma análise a partir de casos do Programa Escola Aberta. Rio Grande do Sul - RS. Revista Brasileira de Ciências do Esporte, 39(1), 24-30. https://doi.org/10.1016/j.rbce.2015.10.018

Franca, R., Goncalves, S, F., \& Rechia, S. (2016) A semana cultural no Colégio Estadual Gelvira Corrêa Pacheco: Uma possibilidade de educação para o lazer Lúdica Pedagógica, 1(23), 63-70. http://dx.doi.org/10.17227/01214128.4157

Fritsch, F. R., Dudel M. B. L., Ubessi, L. D., Kirchne, R. M., Barbosa, D. A., \& Fernande, E. S. (2015) Atividade física, de lazer e avaliação da saúde na perspectiva de usuários em hemodiálise. Revista de Pesquisa Cuidado é Fundamental Online, 7(4), 3263-3273 https://www.redalyc.org/articulo.oa?id=505750948011

Gomes, C. L. (2004) Dicionário crítico do lazer. Belo Horizonte, Minas Gerais. Autêntica Editora. http://www.observatorioqvt.uneb.br/wpcontent/uploads/2015/12/livro-dicion\%C3\%A1rio-cr\%C3\%ADtico-do-lazer-christianne-luce-gomes.pdf

Isayama, H. F., \& Santos, C. A. N. L. (2014) O currículo de cursos técnicos de lazer no Brasil: um estudo de caso da formação profissional. Revista Brasileira de Estudos Pedagógicos, 95(240), 276-30. https://www.scielo.br/j/rbeped/a/9P7VcwrjCt9gzTkXLhDCrXy/abstract/?lang=pt

Isayama, H. F., \& Ungheri, B. O. (2017) Os saberes e a formação profissional em lazer: uma análise no campo das políticas públicas. Revista Brasileira de Estudos Pedagógicos, 98(249). https://doi.org/10.24109/2176-6681.rbep.98i249.2842

Jacob, T. C. Práticas de lazer na sociedade goiana (1906-1920). (2014) Materiales para la historia del deporte,6(12). http://polired.upm.es/index.php/materiales_historia_deporte/article/view/4129

Keitel, L., Kleba, M., \& Sebenello, D. C. (2016) Práticas de lazer e espaços públicos de convivência como potência protetiva na relação entrejuventude e risco. Revista Katálysis, 19(1), 53-63. https://doi.org/10.1590/1414-49802016.00100006.

Labegalini, C. M. G., Rodrigues, D. M., Almeida, E. C., Bueno, S. M., Baldissera, V. D., \& Nogueira, I. S. (2016) Pesquisa-ação educativa no Facebook®: aliando lazer e aprendizado. $\mathrm{v} 37$ (esp), https://doi.org/10.1590/1983-1447.2016.esp.64267

Madeira, L. M., \& Rodrigues, A. B. (2015) Novas bases para as políticas públicas de segurança no Brasil a partir das práticas do governo federal no período 20032011. Revista de Administração Pública-RAP, 49(1), 3-21.

http://bibliotecadigital.fgv.br/ojs/index.php/rap/article/view/42957

Marcellino, N. C., \& Puke, N. (2014) Possibilidades de interface entre lazer e fenomenologia. Movimento, 20(1), 307327.https://seer.ufrgs.br/Movimento/article/view/40321

Marques, S., JR., \& Silva, F. F. (2017). Fatores que afetam o encantamento do cliente do turismo de lazer a partir da experiência em parques temáticos. TurismoVisão e Ação, 19(1), 103-127. https://doi.org/10.14210/rtva.v19n1.p103-127

Melo, M. I. O., \& Dias, K. S. (2014) Parque Farroupilha, a natureza na cidade: práticas de lazer e turismo cidadão. Revista de Turismo Contemporâneo, 2(1). https://periodicos.ufrn.br/turismocontemporaneo/article/view/5472

Mendonca, P. E. M. (2014) Modo de produção da existência: categoria chave para a compreensão da problemática do lazer. Revista HISTEDBR On-Line, 14(57), 353-365. https://www.anped.org.br/biblioteca/item/modo-de-producao-da-existencia-categoria-chave-para-compreensao-da-problematica-do

Menin, D. (2018) A historicidade dos Direitos Humanos e os pensamentos de Bobbio e Arendt na construção do Direito ao Trabalho e ao Lazer. Akrópolis-Revista de Ciências Humanas da UNIPAR, 26(1). https://doi.org/10.35699/1981-3171.2018.1950 
Mielke, G. I., Malta, D. C., Sa, G. B. A. R. D., Reis, R. S., \& Hallal, P. C. (2015) Diferenças regionais e fatores associados à prática de atividade física no lazer no Brasil: resultados da Pesquisa Nacional de Saúde-2013. Revista Brasileira de Epidemiologia, 18, 158-169.

https://doi.org/10.1590/1980-5497201500060014

Minayo, M. C. de S. (2006). Violência e Saúde. Rio de Janeiro: Editora Fiocruz. 134, 2006. http://books.scielo.org/id/y9sxc/pdf/minayo-9788575413807.pdf.

Miranda, P. L. A. (2016) Negociações Impressas: a imprensa comercial e o lazer dos trabalhadores no Rio de Janeiro da Primeira República. História (São Paulo), 35, 1-21. https://doi.org/10.1590/1980-436920160000000099

Miranda, P. D. R., \& Rezende, P. M. (2015). Investigando o consumo de lazer por idosos. Podium Sport, Leisure and Tourism Review, 4(1), 15-31. https://doi.org/10.5585/podium.v4i1.101

Moraes, A. N. de (2017). Atividades culturais e de lazer praticadas por alunos de escolas com diferentes estruturas esportivas em seu entorno. Cinergis. 18(4), 302-307. http://dx.doi.org/10.17058/cinergis.v18i4.11308

Nasser, R. L., Branco, J. C., Lara, D. R., Del Vechio, F. B., Winer, C., Mesquita, P., Souza, L. D. Silva R. A., \& Jansen, K. (2016). Atividade física de lazer e uso de substâncias lícitas em uma amostra populacional de adultos jovens. Ciência \& Saúde Coletiva, 21, 63-70. https://doi.org/10.1590/1413-81232015211.18862014

Nodari, M. P. M., Rosa, E. M., Nascimento, C. R., \& Guerra, V.M (2016). Os usos do tempo livre entre jovens de classes populares. Psicologia - Teoria e Pesquisa, Universidade Federal do Espírito Santo, 32, 09. https://doi.org/10.1590/0102.3772e324215

Pachêco, T. N. P. (2019). Aspectos que demarcam as distintas trajetórias de vida dos (as) jovens na sociedade brasileira durante a vivência do lazer. In: Amorim, P. A. R., Campos, E. A., Couto, A. C. P., \& Lemos, K. L. M. GESPEL em ação no Centro MG da Rede CEDES. Belo Horizonte, MG: Utópica Editoral.

Pegorari, M. S., F. Santos N. M., \& Tavares, D. M. (2015). Prática de atividade física no lazer entre idosos de área rural: condições de saúde e qualidade de vida. Revista da Educação Física/UEM, 26(2). https://doi.org/10.4025/reveducfis.v26i2.25265

Pereira, M. A. S. (2015). Eficácia do direito ao lazer do professor: elemento para manutenção da ordem econômica brasileira. Revista de Direito Econômico e Socioambiental, 6(1), 64-87. https://doi.org/10.26843/direitoedesenvolvimento.v5i10.268

Pereira A. S. et al. (2018). Metodologia da pesquisa científica. UFSM. https://repositorio.ufsm.br/bitstream/handle/1/15824/Lic_Computacao_MetodologiaPesquisa-Cientifica.pdf?sequence $=1$

Pines, A. R., Jr., \& Uvinha, R. R. (2015). Atividade física como opção de lazer: reflexões sobre os jovens frequentadores do SESC Consolação. Educación Física y Deporte, 34(2), 2. http://doi.org/10.17533/udea.efyd.v34n2a04

Pinto, S. M., \& Silva, J. P. C. da (2016). Lazer na juventude: compreensão e prática, no município de Santa Cruz do Capibaribe-PE. Cinergis, 17(1). http://dx.doi.org/10.17058/cinergis.v17i1.7138

Queiroz, AG (2015) "Não tô boa. Preciso passear!": o lazer de moradores de dois serviços residenciais terapêuticos de Belo Horizonte. (dissertação). https://repositorio.ufmg.br/bitstream/1843/EEFF-BB6FCD/1/adriana_gon_alves_queiroz.pdf

Ramos, R.. \& Isayama, H. F. (2009). Lazer e esporte: olhar dos professores de disciplinas esportivas do curso de educação física. Revista Brasileira de Educação Física e Esporte, 23(4), 379-391. https://doi.org/10.1590/S1807-55092009000400007

Rezende, F. H. F. (2019). O bullying na visão dos estudantes de graduação da UFMG. In: Amorim, P. A. R., Campos, E. A., Couto, A. C. P., \& Lemos, K. L. M. GESPEL em ação no Centro MG da Rede CEDES. Utópica Editoral.

Rocha, P. G. (2019). A garantia do direito ao lazer nas "casas lares" de Belo horizonte. In: Amorim, P. A. R., Campos, E. A., Couto, A. C. P., \& Lemos, K. L. M. GESPEL em ação no Centro MG da Rede CEDES. Utópica Editoral.

Romera, L. A. (2008). Juventude, lazer e uso abusivo de álcool. (Doctoral dissertation, Tese (Doutorado em Educação Física) - Faculdade de Educação Física da Unicamp, Campinas, SP). http://repositorio.unicamp.br/bitstream/REPOSIP/275170/1/Romera_LianaAbrao_D.pdf

Sá, F., Silva, N., Leão, L., \& Maia, M. (2018). Hábitos de lazer em adultos praticantes de musculação. RBONE-Revista Brasileira de Obesidade, Nutrição e Emagrecimento, 12(74), 716-721. http://www.rbone.com.br/index.php/rbone/article/view/773

Schwartz, G. M. \& Tavares, G. H. (2014). Políticas públicas de esporte e lazer no Brasil e em Portugal: a gestão do conhecimento em foco. Revista da Educação Física - UEM, 25(4). https://doi.org/10.4025/reveducfis.v25i4.22533

Silva, A. O., da Silva, A. F., \& Couto, A. C. P. (2019). Cada jovem sente a dor e a delícia de trabalhar no que quer: análise da relação das juventudes e o trabalho. In: Amorim, P. A. R., Campos, E. A., Couto, A. C. P., \& Lemos, K. L. M. GESPEL em ação no Centro MG da Rede CEDES. Utópica Editoral.

Sposito, M. P. (1994). A sociabilidade juvenil e a rua: novos conflitos e ação coletiva na cidade. Revista Sociologia Universidade de São Paulo - USP, 5 , 18. http://www.scielo.br/pdf/ts/v5n1-2/0103-2070-ts-05-02-0161.pdf

Teixeira, R. da C. (2018). A Associação Nacional das Torcidas Organizadas do Brasil na arena pública: desafios de um movimento coletivo. Antípoda. Revista de Antropología y Arqueología, 30.

Trotta, F. (2016). O funk no Brasil contemporâneo: uma música que incomoda. Latin American Research Review, 86-101. 